International Journal of Engineering \& Technology, $7(2.21)(2018) 327-330$
International Journal of Engineering \& Technology
SPC
Website: www.sciencepubco.com/index.php/IJET
Research paper

\title{
Data management with PMS in hotel industry
}

\author{
Hussam Mohideen Moyeenudin ${ }^{1 *}$, Shaik Javed Parvez ${ }^{2}$, R. Anandan ${ }^{3}, K_{\text {Kumar Narayanan }}^{4}$ \\ ${ }^{1}$ School of Hotel \& Catering Management, Vels Institute of Science, Technology and \\ Advanced Studies (VISTAS), Pallavaram, Chennai, India. \\ ${ }^{2}$ Department of Computer Science and Engineering, Vels Institute of Science, Technology and \\ Advanced Studies (VISTAS), Pallavaram, Chennai, India. \\ ${ }^{3}$ Department of Computer Science and Engineering, Vels Institute of Science, Technology and \\ Advanced Studies (VISTAS), Pallavaram, Chennai, India. \\ ${ }^{4}$ Department of Computer Science and Engineering, Vels Institute of Science, Technology and \\ Advanced Studies (VISTAS), Pallavaram, Chennai, India. \\ *Corresponding author E-mail: moyeenudin@gmail.com
}

\begin{abstract}
The rapid growth of hotel industry has increased the usage of data with the help of property management system (PMS). It deals with sharing information in a systematic procedure within the organization. The major benefit of data management with PMS is the information can be easily stored and shared between staff members; it is useful during recruitment and when an employee goes on vacation, gets sick, or leaves the organization, It comprise with procedure of work, duties and responsibilities, initiatives, performance, documentation, forming business strategies and systems which enhance the organization. Data management helps in storing the data for handling plans and on methods of executing and developing policies for various situations in hotel. Data Management is a way of managing knowledge base and making it accessible for specific purposes in any industry, also to improve the quality of performance and standards, by various methods of data application in Management practices which involves in understanding the industry and effectively utilizing data in learning and implementing policies of an organisation. This article describes about how Data Management in hotels works with property management system (PMS) and the advantages of having PMS in hotel Industry. This paper also focuses on the advancement in PMS with cloud technology for future demands.
\end{abstract}

Keywords: Call accounting system (CAS), central reservation system (CRS) data management, property management system(PMS), energy management system (EMS), global distribution system (GDS), internet distribution system (IDS).

\section{Introduction}

In hotel industry, the business requirements are advancing rapidly and this environment is also becoming more competitive with unpredictable competitors strategy. The success of a hotel is merely depends upon the ability to adjust with the dynamics of this industry and the business environment, by making practical and constructive decisions to utilize the skills and knowledge of employees in proper channel. PMS is one of the best data management software that helps in recognizing the knowledge of employees and being as source of information in hotel Industry to increase the business and its features helps in managing the property effectively and it can be upgraded according to their guest service with a much higher facilities and also have access to all staffs with proper rights in their respective departments. Data Management widely in hotel industry is work with a property management system to accomplish the basic objectives of the hotel. It is not only storing and sharing the data's of management, it also acts as a comprehensive tool in developing hotel business extensively.

\section{Methodology/analysis}

Data comparisons collected from five-star hotels in Chennai. Secondary Data has been collected by literature survey.

\section{Property management systems (PMS)}

Property management system is replacing paper based registers which is used at hotel industry in the earlier stages. Due to the rise in technology there are so many PMS vendors are available in market, PMS are available by hotel design and according to the size and type of the property. Since it is expensive not all hotels are afford to buy it. Perhaps, some generalization about property management systems may illustrate the nature of front office application. A property management system consists of set of automated software modules that can support a variety of activities in front office. The major front office modules are designed to help the employees to operate the functions are as follows:

- Reservation module

- Room module

- Guest accounting module

- General Module 


\section{Reservation module}

The reservation management module provides room status records related to the time and date of guest check in, check out, type of room and plan opted by guest. Because in hotels guest prefer to have a food plan along with their accommodation like American plan, Modified American plan, Continental Plan and European Plan. Reservation module facilitates a hotel to accelerate the action of room request and bring out the right room to the guest on time, revenue, and forecasting reports. This is helpful in knowing room availability and reservation status and automatically transmits confirmation of a reservation via email, fax or by other Internet media. Mostly international group of hotels engage in remote reservation networks also known as global distribution systems (GDSs), Internet distribution systems (IDSs) central reservation systems (CRSs).

In Addition, GDSs can grasp, process and forward reservation details developed by tour operators, travel agents and Airline agencies. The most familiar GDSs used by hotels worldwide are sabre, Galileo, and world span along with that one more intermediary used is IDSs website that represents hotel companies and sells accommodations overnight on a commission basis or on package basis. IDSs obtain guest reservation data and automatically connects to hotel property management system through a GDSs or CRSs.

Reservation module helps in tracing the deposit due, finding the guest who has not deposited the advance then raising request deposit and record deposit payments made and also it helps in posting advance deposit towards guest room during the time of reservation.

\section{Room module}

Room module manage the present status of rooms and furnish the details on that; it allows the staff to manage hotel rooms and floor plan with a entire layout of a hotel, also it shows the rooms under maintenance schedule, rooms in long term stayovers, add information on rates, assigning the room during registration, and assist front office personal to correlate with guest services. A room module can also be used to administer instant passage to room availability data during certain conditions of registration process. This software also helps and assists front office staff during registration and reservations. In Hotel, at times rooms are temporarily blocked for renovation, repair and for maintenance job or cleaning procedure, the number of rooms available in the reservation display is automatically decreased to the actual available rooms, this module also assists in controlling future room inventory and ensure that all guests have rooms ready when they check in to hotel.

\section{Guest account module}

The Guest account module keeps the data's of hotel guest on their payments and the transactions made during their stay, which improves the visibility of guest accounts to hotel. The guest accounting module monitors predetermined guest credit limit and brings out resilience through split, multiple folio format and eradicate the need of a manual folio, vouchers, reports and registers. At the time of checkout, previously authorized outstanding account balances are automatically transferred to an appropriate file for future reference. When the hotels food and beverage outlets, business centre, fitness and spa are connected to the front office remote point of sale modules can communicate guest charges to property management system with the help of Internet.

\section{General module}

General module application used to generate the reports of various modules like guest transactions on accounts receivable and accounts payable application, which monitors the limits of guest billing and accounts. This is also relate with human resource module which include payroll accounting, personal records of employees, performance evaluation of employees, pay distribution and tax withholdings and deductions, Training and development, duties and responsibilities according to the employee's position. Property management system is comprised with other individual modules like energy management system, call accounting system, capacity management, point of sale and electronic door locking system. This made property management system as a most beneficial application in hotel nowadays.

\section{Point of sales}

The point of sale accepts transaction other than accommodation. These includes restaurant, bar, banquets, business centre, discotheque, health club, night club etc. Each point of sale equipped with a stand-alone automated support for billings. Data's are also transferred to other modules for processing master folio in front office.

\section{Call accounting system (CAS)}

Hotels provide telephone facility to their guest. The room guest can make local and international calls from the comfort of their rooms. The call accounting system is measuring the number of calls made by hotel guest and the duration of the call with the help of automated accounting system that counts and tracks the details of all outgoing and incoming calls made by the guest. The calls are automatically posted in the respective caller's account and electronic guest folios.

\section{Energy management system (EMS)}

Energy management system is a typical function which shut down the operation of equipments those are not in use for a period of time and automatically manages room temperature, air movements in public spaces and guest rooms. In addition, it reduces the humidity when required through a rooms management interface in public areas. An Energy management system is programmed to minimize the usage of electricity and fuel according to the requirement and necessity, this control system designed to manage and operate automatically of those mechanical equipment which consume energy. EMS also gives suggestions and prioritises which room has to sell to save energy For example, a hotel has 400 rooms and 70 percent of occupancy is forecasted where rooms are assigned in lower floors and the top floor is not occupied then the power consumption in the top floor is fully minimized.

\section{Electronic locking system (ELS)}

An electronic locking system is interfaced with room management module. This system helps the hotel to control access to guest rooms. Only a person with a proper key card coded for the specific room can enter that room. The coding made in key are unique and only function till the guest stay in that room, after the guest check out it will become non functional. This electronic key locking system is networked with PMS, the key code generated will also be deleted and a front desk person is able to code the room key for the next guest arrival.

\section{Selection of PMS}

A system that works well for one down town hotel may not meets the needs of a down town hotel in another city or a resort in same area. An inappropriate PMS will produce control reports that are not useful to management. A Selection of PMS is done by knowing the facilities and requirements of hotel operations. If the 
management has estimated and gathered the required data to operate the hotel concerning to management needs, as well as it has to eventually justify how the PMS helps in guest service. How quick the vendor will provide service in case of emergency. Hotels have to focus on PMS which satisfy the guest because it is a bridge that provides overall guest satisfaction. The major task is to understand the type of guest who visits the hotel, to know their expectation and behaviours in order to improve their experience which matches their needs along with a hotel's ability for selecting a proper PMS.

There are several companies that provide PMS software to hotels, with their own unique features according to the need of the hotel and its requirements, to name the few major PMS software providing companies to their clients in the market. Micros this is PMS software it provide solutions to hotel industry through:

- Opera Enterprise solution

- Micros Fidelio

- Amadeus PMS

Can be integrated with hotel front office, sales/marketing, and financial management functions.

IDS Fortune PMS provides centralised data, colourful displays; a single database keeps all aspects of management, ensuring transparency and flexibility.

SHAWMAN PMS is unified front office software that can manage many hotel outlets and handle guest reservations together and with auto confirmation manager.

The trend confirm that hotels evolved rapidly with various themes and facilities simultaneously property management system also will turn in to a cloud-based system, that helps hoteliers in reducing manpower and technical support by its access and flexibility also avoids unexpected grievance and failure with the improved cloud based PMS

\section{Recent development in hotel PMS}

\section{User friendly operation}

It works with Internet; there is no installation difficulties and complication to install software in computer. PMS will be updated automatically and the user can access the latest features of PMS.

\section{Advanced web reservations}

A unified online reservation system helps in various types of works by automatically allocating the room inventory separately from Web bookings. During the time of room reservation from hotel website or with the help of global distribution system, the number of occupied, checked out and under maintenance work will be updated automatically.

\section{Frequent data backup}

After the reservation process the data need to be kept secured, due to advanced property management systems the data's are stored automatically in a computer and remote server with the help of internet. It also protects the data from direct physical damage, viruses, theft, and from spyware.

\section{Mobile access}

PMS can be accessed through any android, Macintosh, windows mobile phone or tablets in order it is connected to the Internet, that makes to manage the property at anytime and from anywhere. Reservations, check-ins, checkouts and front office reports are always at the fingertips.

PMS also manage the discounts and special rates for business clients, airlines, tour operators, travel agents and for regular guests.

Group reservations with services such as tours, pilgrimage will be offered with package rates.

\section{Group bookings}

Hotels takes reservations for group check-ins and block number of rooms required for the specified group with the help of PMS automatically the charges are applicable to a master invoice or to individual reservations. The payments can be made by a group or as separate payments to individual reservations. It creates an access code to a group, and let them book online through hotel website or booking engine.

\section{Electronic signature}

The advanced feature in recent days is electronic signature capture that allows the guests to sign during check-in and check outs as well as at food and beverage department receipts or registration cards using an electronic device which capture the signature such as a tablet or Smartphone. Front office staff has to log into their PMS system with a tablet or Smartphone to access the electronic signature capture facility.

\section{Administration module}

This application is specially designed for international chain group of hotels with this module hotel can centralizes availability searches for guest profile, guaranteed and non guaranteed reservations and the business reports of connected properties. The data's from various locations can be accessed through this administration module it also track the details of back-office administration and improves internal communication and customer service.

\section{Front office reports}

Front office reports ensure available rooms are ready prior to guest arrival and that any special requests like type of plan opted by guest are fulfilled and it will be updated in the room status and occupancy report.

\section{Back office and Audit}

In this module there is a facility to track receivables, Bills of POS, payouts, profit/loss, deposits, assets and liabilities of hotel, guest profiles, vendors, service and income taxes can be listed and updated, tallying guest bills to zero out.

\section{Social media}

The pervasiveness of social media has been spreading throughout the world in different arena; the hotel industry has also identified the need for systems to integrate with social media sites' to share the information instantly. The hotel PMS connected with social media will enable hotels to stay on top of ratings among other hotel in a particular location and it also helps in responding to guest comments on sites such as Whatsapp, Facebook, Twitter, Instagram and more. Guests prefer to respond, react and interact often on social sites. Online reviews of hotel guest their likes and interest will be highlighted during branding. The interaction will be a requirement to compete with other properties and it is not just from one social expert on property, but rather a variety of designated employees will be expected to have the tools to manage their social sites they also need to monitor and analyze social media updates to improve the quality of the property.

\section{Finding}

PMS has a major role in developing hotels business and Guest satisfaction with their unique features and facilities with the help of yield management and knowing the guest feedback. Selection 
of PMS should be with need analysis of the hotel; Results are based on the interpretation of data collected by the hotels in Chennai.

\section{Conclusion}

Data Management become a major task in hotel industry as the data entered on the PMS by hotel and data entered from guests on the website will be specific, Hotel PMS need to integrate according to the demand and requirement of the guest with their preferences and also hoteliers must know which PMS is suitable for their property. By having proper PMS hotel can make good profit and earn guest satisfaction. The PMS vendors should identify the need on developing and enhancing their cloud-based technology and with the ability to exchange the information by the available data in a secure and safest way and that software will adapt the changes and amendments in all departments of hotel. The most familiar PMS vendors are already in the process of making cloud based PMS software to hotel industry with this the security level data will be increased being as user friend and easy installation a hotel can reduce the cost for manpower and technical support . After the implementation of new software, a training is required for the employees to make easier job more faster on new advanced PMS a time period need to allocated to the employees to become comfortable and familiar with this new software.

\section{References}

[1] Erdem M \& Jiang L, "An overview of hotel revenue management research and emerging key patterns in the third millennium", Journal of Hospitality and Tourism Technology, Vol.7, No.3, (2016), pp.300-312

[2] Bardi JA, Hotel front office management, John Wiley \& Sons Ltd, (2003).

[3] Awad EM \& Ghaziri H, Data Management.

[4] Tewari JR, Hotel front office: operations and management, Oxford University Press, (2009).

[5] Kasavana ML \& Brooks RM, Managing front office operations, Educational Institute of American Hotel \& Motel Association, (1998).

[6] https://en.wikipedia.org/wiki/Property_management_system

[7] http://www.pmscloud.com/

[8] http://www.littlehotelier.com/how-to-choose-an-all-in-one-pmssystem-for-small-hotels/

[9] http://www.hoistgroup.com/en/products/hotel/hotelsystems/booking-system-for-hotels/

[10] https://www.oracle.com/industries/hospitality/products/operacloud-services.html 